\title{
Retinoblastoma by AJCC v8 Pathologic Stage
}

National Cancer Institute

\section{Source}

National Cancer Institute. Retinoblastoma by A/CC v8 Pathologic Stage. NCI Thesaurus.

Code C140756.

A term that refers to the pathologic staging of retinoblastoma according to the American Joint Committee on Cancer, 8th edition. 